\title{
DOCÊNCIA NO ENSINO SUPERIOR: FORMAÇÃO DOCENTE, IDENTIDADE E PRÁTICA PEDAGÓGICA
}

\author{
Vando Madureira Ferreira ${ }^{1}$
}

\begin{abstract}
RESUMO: Este artigo é o resultado de uma pesquisa bibliográfica sobre a docência no ensino superior, cujo objetivo é orientar atuais e futuros profissionais sobre a identidade e a prática da profissão docente no ensino superior. Para tanto, foram selecionadas como referências artigos e livros publicados nos últimos dezesseis anos, que pudessem contribuir para a compreensão da realidade e das necessidades relativas ao tema. Os resultados apontam que a qualidade de ensino da universidade e o trabalho do docente realizado em sala de aula, são de uma estreita relação. $\mathrm{O}$ desenvolvimento de capacidades e habilidades de pensar e aprender estruturados dentro de um ambiente adequado é necessário para promover mudanças e inovações, levando a uma melhoria significativa dentro de sala de aula. Os cursos de ensino superior devem dar o suporte para os novos profissionais e cidadãos. Somente com a prática e desenvolvimento da atividade intelectual realizada de forma concreta e participativa tem-se a formação do ser integral. A metodologia do ensino superior deve levar o estudante a entender os mecanismos que levam ao aprendizado de forma consciente e independente, formando no estudante estratégias cognoscitivo geral a cada ciência, em função de analisar e resolver situações problemas.
\end{abstract}

Palavras-chaves: Formação docente. Identidade. Prática. Capacidades. Habilidades.

ABSTRACT: This article is the result of research literature on teaching in higher education, whose goal is to guide current and future professionals on the identity and practice of the teaching profession in higher education. For both, were selected as reference books and articles published over the past sixteen years, which could contribute to the understanding of reality and the needs on the topic. The results indicate that the quality of university teaching and work of teachers conducted in the classroom are closely linked. The development of skills and abilities to think and learn in a structured environment are necessary to promote appropriate changes and innovations leading to a significant improvement in the classroom. The courses of higher education must provide support for the new professionals and citizens. Only with practice and development of intellectual activity conducted in a participatory and practical training has to be integral. The methodology of higher education should lead the student to understand the mechanisms that lead to learning of a conscious and independent. Forming student in general cognitive strategies to each science, according to analyze situations and solve problems.

Keywords: Teaching profession. Capabilities. Skills. Teacher training.

\footnotetext{
${ }^{\text {I }}$ Licenciatura Plena em pedagogia: Faculdade Mantenense dos Vales Gerais INTERVALE-202I Licenciatura Plena em História pela Universidade do Acaraú UVA 20ı. Pós-Graduado em Gestão Escolar: Orientação e Supervisão. Faculdade Intervale 2021 Pós-Graduando em Docência do Ensino Superior pela faculdade FACEL- 2019. Pós-Graduado em Educação Especial Inclusiva pela Faculdade de Teologia e Ciências Humanas FATECH 2018. Pós-Graduado em Educação Profissional pelo Instituto Federal de Tecnologia do Estado do Amapá IFAP-2or6. Pós-Graduado em História Africano e Afro-brasileiro pela Faculdade ATUAL-2013.E-mail: ferreiramadureira@hotmail.com
} 


\section{INTRODUÇÃO}

A constante reflexão sobre o fracasso da educação e a necessidade de profissionais desafiadores, resolutos nas questões impostas por suas profissões, sempre são um dos pontos cruciais em debates e polêmicas sobre o desenvolvimento da educação superior no Brasil. Levam ao estudo e à reformulação das questões relativas ao trabalho docente no ensino superior, bem como, o olhar dessas questões sobre um novo prisma. Este trabalho tem como objetivo reconhecer os pilares básicos para a formação da identidade, da prática e da profissão desse docente.

Pensar em educação sem pensar no profissional que atua nela de nada adiantaria, pois a educação, como atividade relacional, somente se realiza por meio da ação entre pessoas: de um lado, o profissional docente; de outro, o aluno. Daí a importância da formação desse profissional em busca do aperfeiçoamento não só da sua didática, mas também, da sua habilidade de fazer com que os educandos sintam-se motivados, enfim, sintam-se parte do processo de ensino e de aprendizagem.

A busca de elementos que pudessem traçar o perfil do profissional adequado para a docência na Educação Superior foi o norte para o desenvolvimento desse trabalho. Parte da ideia de que o professor universitário, além de professor de matérias específicas, é também um professor que vai além desse limite, um professor pesquisador, que seja capaz de fazer ligações necessárias entre o saber sistematizado e o contexto de vida. Que faça com que os acadêmicos saibam como e onde procurar as saídas para situações que necessitam de estudo em maior profundidade e criatividade de soluções, permitindo-os serem capazes de construir, modificar e ampliar seus conhecimentos, tornando-se sujeitos de sua aprendizagem.

Assim, este estudo promove reflexões sobre alguns aspectos que já foram publicados sobre a docência do ensino superior, bem como sobre possibilidades para aprimorar a prática docente, sobre as suas mudanças nos últimos anos, tendo em vista o trabalho desse professor dentro do espaço acadêmico ser o responsável pela formação dos profissionais de diversas áreas do saber, os quais são colocados no mercado de trabalho todos os anos. 


\section{IDENTIDADE PROFISSIONAL: PERFIL DO PROFESSOR DE ENSINO SUPERIOR}

A identidade do professor universitário por vezes se perde nas funções que desempenha na instituição e na sociedade. As exigências que caracterizam o exercício da profissão de professor ficam, por vezes, escondidas e não bem definidas dentro do próprio corpo docente, em função da diversidade de formações de origem, das afinidades que se estabelecem por área de saber e dos diferenciais entre as várias universidades.

Corrobora para esse processo, o fato da inexistência de uma formação específica como professor universitário. Embora a Lei de Diretrizes e Bases da Educação Nacional LDB, de 1996, estabeleça que essa formação se realize, preferencialmente, em programas de mestrado e doutorado (BRASIL, 1996), por outro lado, é conhecido o fato de que esses cursos têm foco maior na formação do pesquisador, em detrimento da formação pedagógica (BAZZO, 2006).

Segundo Pimenta e Anastasiou (2002), embora os professores universitários possuam experiências significativas na área de atuação, ou tenham um grande embasamento teórico, predominam, no geral, o despreparo e até um desconhecimento científico do que seja um processo de ensino e de aprendizagem.

Acreditava-se que para ensinar na universidade fosse suficiente o domínio de conhecimento específico - pesquisa ou exercício profissional no campo. Segundo Masetto (1998, p. 36), até a década de 1970, "praticamente exigia-se do candidato a professor de ensino superior o bacharelado e o exercício competente de sua profissão", com base no princípio de "quem sabe, sabe ensinar".

Portanto, para alcançar melhores resultados no ensino superior, é necessário produzir novos conhecimentos com a preocupação de formar e de desenvolver profissionalmente os professores universitários, pois, esses são essenciais nos processos de mudança dentro das universidades e das sociedades em que estão inseridos. Nesse aspecto, é preciso deixar a ideia de que o conhecimento específico é o principal esteio de sua docência.

Conforme Libâneo (1998), a Pedagogia é um campo de conhecimento sobre a problemática educativa na sua totalidade e historicidade e, ao mesmo tempo, uma diretriz 
orientadora de ação educativa que deve ser trabalhada. $O$ pedagógico refere-se às finalidades da ação educativa, implicando objetivos sociopolíticos a partir dos quais se estabelecem formas organizativas e metodológicas da ação educativa.

A didática, como uma área da pedagogia que investiga os fundamentos, condições e modos de realizar a educação mediante o ensino, possibilita que os professores de áreas específicas "pedagogizem" suas ciências, ou seja, articulem todos os elementos para que aconteça a aprendizagem instituindo assim, os parâmetros pedagógicos. É preciso destacar, porém, que diferentes conhecimentos são de importância fundamental para o exercício da docência em Educação Superior: pedagógico-didáticos, da área específica e da experiência (LIBÂNEO, 1998).

Os aspectos didáticos e pedagógicos compõem um campo de estudo que se ocupa de refletir sobre a prática docente, ou melhor, dos aspectos que estão envolvidos no processo de ensino e de aprendizagem. Com base nos estudos de Azzi (2000) e Caldeira (1995), a didática pode ser percebida como uma espécie de metalinguagem, em que, por meio do exercício da docência, há a possibilidade de reflexão sobre a prática realizada. A linguagem e os saberes se encontram em autores diferentes, cada qual com ângulos de visão diferentes sobre a temática da docência no ensino superior, o que vem a fortalecer as questões de mudanças, encorajando ações para a defesa da formação de professores qualificados para o desenvolvimento da prática docente nas universidades.

$\mathrm{Na}$ maioria das vezes, tradicionalmente, os professores do ensino superior se identificam por meio da sua área de atuação e não como professor do curso no qual leciona. Quando se reflete sobre o perfil do professor universitário brasileiro atualmente, no entanto, pode-se perceber que a valorização de sua formação pedagógica, muito embora não seja nova nos textos legais, na prática, é algo recente no processo de seleção e contratação dos mesmos. Hoje em dia é comum analisarem currículos com olhar para os profissionais que foram durante sua vida acadêmica e se formados para serem professores. O valor da experiência no magistério e os cursos de formação para a docência são vistos com um olhar mais cuidadoso pelas instituições de ensino superior (CALDEIRA, 1995).

Observa-se, entretanto, que alguns professores se caracterizam de um modo geral, como especialistas em seu campo de conhecimento, entendendo que a sua formação 
didático-pedagógica poderá ser adquirida naturalmente ao longo de sua experiência docente (AZZI, 200o).

Sem querer desmerecer o valor da experiência acumulada na prática do magistério, pode-se afirmar que o planejamento e a condução do ensino requerem não apenas o conhecimento do conteúdo, mas também, a compreensão do processo por meio do qual ocorre a construção do conhecimento por parte dos alunos, sem a qual, a forma de apresentação dos conteúdos pelo professor fica altamente prejudicada (CALDEIRA, 1995).

Para Pimenta e Anastasiou (2002), é preciso considerar que a atividade profissional de todo docente possui uma natureza pedagógica, isto é, vincula-se a objetivos educativos de formação humana e a processos metodológicos e organizacionais de construção e apropriação de saberes e modos de atuação.

Por isso, para ensinar, o professor necessita de conhecimentos e práticas que ultrapassem o campo de sua especialidade. Segundo Libâneo (2004, p. 122), que reitera Davydov, "a coisa mais importante na atividade científica não é a reflexão nem o pensamento, nem a tarefa, mas a esfera das necessidades e emoções”.

Assim, a necessidade de desenvolver ações de formação continuada para o provimento das deficiências de muitos dos profissionais que atuam na Educação Superior é urgente, especialmente porque muitos atuam também na formação de docentes para a Educação Básica. Além disso, com o advento de novas propostas educativas e o perfil inovador exigido dos futuros profissionais, torna-se imprescindível a formação de professores reformulando os valores e a didática, com vistas à qualificar o processo educativo e profissionalizar a ação docente.

Começou-se a perceber que assim como para a pesquisa se exigia desenvolvimento de competências próprias, e a pós-graduação buscou resolver esse problema, a docência no ensino superior também exigia competências próprias que desenvolvidas trariam àquela atividade uma conotação de profissionalismo e superaria a situação até então muito em contradição de se ensinar 'por boa vontade', buscando apenas certa consideração pelo título de 'professor de universidade', ou apenas para 'complementação salarial', ou ainda somente para se 'fazer alguma coisa no tempo que restasse do exercício da outra profissão" (LIBÂNEO, 2004, p.125).

Isto significa que o processo de construção de conhecimento, para o professor universitário, é permanente e é, possivelmente, o caminho por meio do qual poderá 
mostrar aos seus alunos a necessidade de atualização contínua. A partir das exigências e possibilidades do processo de globalização do mundo de hoje, bem como da revolução nas tecnologias de comunicação informação, esse professor foi transformado em um educador, cujo papel vai além de seu conhecimento específico. Neste contexto, exige-se que seja um professor pesquisador, que demonstre aos seus alunos o interesse em sempre aprender e, concomitantemente, o interesse em ensinar num processo dinâmico (LIBÂNEO, 2004).

Segundo Lima (2000), a preocupação com a formação do professor pesquisador estaria fundamentada na intenção de tirar a educação apenas da transmissão de conhecimento já formulado. Para tanto, a pesquisa possibilitaria aos professores exercerem um trabalho com os alunos com o fim de formular novos conhecimentos ou o questionamento tanto sobre a validade quanto sobre a pertinência dos já existentes.

É importante ressaltar também que, segundo Lima (200o), pode-se definir o professor como aquele profissional que ministra, relaciona ou instrumentaliza os alunos para as aulas ou cursos em todos os níveis educacionais. Segundo suas concepções, o professor-pesquisador, é aquele que exerce a atividade de buscar reunir informações sobre um determinado problema ou assunto e analisá-las, utilizando para isso o método científico com o objetivo de ampliar o conhecimento de determinado assunto, descobrir algo novo ou refutar conjecturas anteriores.

Portanto, para realizar um trabalho didático-pedagógico condizente com a realidade em que está inserido, o professor deve ser crítico e perspicaz para estimular seus alunos, sem que estes percebam que estão sendo provocados criticamente; ético, uma vez que o professor é formador de opinião; ter vocabulário ilibado; ser reflexivo da prática constante de seu trabalho; reconhecer a cultura de seus alunos; enfim, ele deve conhecer seu campo de atuação e ser capaz de permitir aos seus alunos que se apoderem de seus ensinamentos com criticidade, tornando-os parte de um processo de construção de seus próprios conhecimentos.

\section{AMPLIANDO A IDEIA DE PRÁTICA EDUCATIVA}

Ensinar é uma prática social ou, como Freire (1996) imaginava uma ação cultural, pois é na interação entre professor e aluno que se concretiza a prática reflexiva da cultura e dos contextos sociais a que pertencem. Ser professor significa, antes de tudo, ser um 
sujeito capaz de utilizar o seu conhecimento e a sua experiência para desenvolver-se em contextos pedagógicos práticos preexistentes.

Com o advento das análises das práticas pedagógicas como prática social, resta indagar: como chegamos ao profissional docente de que necessitamos? Por meio do pensamento analítico sobre os conteúdos interdisciplinares (politécnicos) ou fragmentados; sobre a necessidade de união entre teoria e prática enquanto metodologia; e, ainda, a democracia enquanto gestão.

De acordo com a visão de Paulo Freire (1996), percebe-se que a ideia de prática educativa é a busca de alternativas e propostas que devem ser uma constante em nosso dia a dia, no sentido de resgatar o "homem", o "cidadão" e o "trabalhador" da alienação de seu "ser", seu exercício de cidadania e sua dignidade.

As propostas pedagógicas devem ser alternativas de "hominização" em contraposição ao processo de relações econômicas, que se definem em alienação do homem e expropriação de seu saber. Assim, não se pode reduzir o conceito da prática educativa às ações de responsabilidade somente do professor e que, normalmente, ocorrem em sala de aula. (FREIRE,I996)

O ato de educar, a ação educativa, transcende às ações dos professores e extrapola os limites físicos da sala de aula, mas vale ressaltar que a interação professor e aluno são imprescindíveis e importantes no processo educacional durante todo ciclo ou etapa de formação cidadã. Não é possível ensinar nada sem partir de uma ideia, de como as aprendizagens se produzem. Por trás de qualquer prática educativa sempre há uma resposta a "porque ensinar" e "como aprender". Não basta que os alunos se encontrem frente aos conteúdos para aprender, é necessário que diante destes possam atualizar seus esquemas de conhecimentos, compará-los, identificar semelhanças e diferenças, integrálos, comprovar que os resultados têm certas coerências. É preciso que percebam que uma pessoa para se relacionar depende das experiências vivenciadas nas instituições educacionais, um dos lugares preferenciais para estabelecer vínculos e definir concepções sobre si mesmo e os demais. (FREIRE, 1996)

Zabala (1998) explicita que a ordenação articulada das atividades seria o elemento diferenciador das metodologias e que o primeiro aspecto característico de um método seria o tipo de ordem em que se propõem as atividades. Ressalta que o parcelamento da prática 
educativa tem certo grau de artificialidade, explicável pela dificuldade em encontrar um sistema interpretativo adequado, que deveria permitir o estudo conjunto de todas as variáveis incidentes nos processos educativos.

Na sequência, Zabala (1998) considera a importância das intenções educacionais na definição dos conteúdos de aprendizagem e o papel das atividades que são propostas. Alguns critérios para análise das sequências reportam que os conteúdos de aprendizagem agem explicitando as intenções educativas, podendo abranger as dimensões: conceituais; procedimentais; conceituais e procedimentais; ou conceituais, procedimentais e atitudinais. Parece elementar retomar conceitos de formação básica, mas a continuidade desse desenvolvimento se dá no ensino superior e com maior responsabilidade, visto que nessa etapa o estudante deve se sentir relacionado com o que estuda e com as finalidades para as quais está se formando.

Essa análise nos propõe alguns questionamentos, tais como: há atividades que nos permitam determinar os conhecimentos prévios? Há atividades cujos conteúdos sejam propostos de forma significativa e funcional? Há atividades em que possamos inferir sua adequação ao nível de desenvolvimento de cada aluno? Há atividades que representem um desafio alcançável? Provoca-se um conflito cognitivo e que promove a atividade mental? Somos motivadores em relação à aprendizagem dos novos conteúdos? Estimula-se a autoestima e o autoconceito? As ações em sala ajudam a adquirir habilidades relacionadas com o aprender a aprender, sendo cada vez mais autônomo em suas aprendizagens?

Em relação às questões levantadas, convém expor sua relevância para a docência no ensino superior, pois cada vez mais temos professores inexperientes acerca da relação entre ensino e aprendizagem. Assim, como podemos formar docentes para a Educação Básica se não damos o exemplo em nossas próprias faculdades e universidades?

Consideramos também outra unidade de análise, as sequências de conteúdo, que requer uma interação entre as dimensões de conceito, procedimento e atitude. Assim, com ênfase no conceitual, a sequência do conteúdo deve estimular o educando a estabelecer suas próprias conjecturas a respeito de sua função na sociedade e de sua responsabilidade frente ao seu papel de educador e formador.

Pode-se dizer que o professor, na docência do ensino superior, deve conduzir a própria prática para a realização de formar por meio do exemplo os novos profissionais, em 
especial os novos docentes, sem deixar que suas limitações comprometam o processo, fazendo delas ponte para o seu crescimento e desenvolvimento dos outros.

\section{FORMAÇÃO DO PROFESSOR DE ENSINO SUPERIOR - UM PROFISSIONAL DA EDUCAÇÃO}

Mesmo em torno das discussões sobre a necessidade de formação pedagógica do professor universitário, percebe-se que ainda restam parcelas da comunidade e indivíduos responsáveis pelas políticas públicas educacionais nacionais que entendem o preparo pedagógico para o ensino superior como algo secundário.

Para o ensino superior não há um curso específico de formação a docentes regulamentados, como em outros níveis. O artigo 66 da Lei de Diretrizes e Bases de 1996 (BRASIL, 1996), admite que esses profissionais sejam preparados em cursos de pósgraduação, prioritariamente em cursos stricto sensu os quais, porém, não são obrigatórios. A Lei deixa lacunas para interpretações dúbias, ou ainda pior, que sejam sanadas de acordo com os estatutos e regimentos de cada instituição de ensino superior.

Saviani (1998) evidencia sua preocupação com a formação pedagógica do professor universitário, citando detalhes acerca da necessidade de capacitação para o uso de modernas tecnologias de ensino. Já prevendo, na década de 1990, as necessidades de hoje e sabedor de quão importante é a relação entre professor e aluno, ele anteviu os problemas pelos quais passam o ensino superior hoje, tais como o uso das novas tecnologias, o crescimento das diferenças sócio-culturais acentuadas dentro dos ambientes de ensino superior e o desenvolvimento de uma subclasse de ditos profissionais da educação que não são formados como educadores, mas, detém o conhecimento necessário para a formação de novos profissionais.

Na mesma linha, para Pimenta e Anastasiou (2002), a Lei não concebe o processo de formação para a docência no ensino superior com todo o rigor que necessita. Saber dialogar com a realidade e os alunos, levá-los à construção consciente da ética, da cidadania, das relações político-sociais e afetivas são fundamentais no exercício das atividades pedagógicas. Todas juntas em uma única aula, na qual, além de possibilitar o aprendizado sobre o rigor característico de cada ciência, o professor possa revelar por meio 
de suas ações na sociedade um profissional competente e múltiplo nas várias relações que necessita desenvolver durante sua atuação.

Constata-se, porém, que os professores do ensino superior, em muitos casos, se identificam profissionalmente como engenheiro, advogado, médico, que dão aula no ensino superior. Isso mostra, de um lado, certa valorização social do título de professor universitário; porém, de outro, uma valorização maior de sua competência como profissional para o mercado de trabalho; isto é, ser apenas professor universitário parece ter pouco valor; mas ser médico professor, dentista professor, advogado professor, engenheiro professor ou outro, rende prestígio e status no exercício de sua profissão, mas sem o caráter formal da profissão de professor e todas as peculiaridades atinentes a esta função (VASCONCELOS, 1998).

Aos profissionais, não só da educação, a formação continuada tem, entre outros objetivos, propor novas metodologias e colocar os profissionais a par das discussões teóricas atuais, com a intenção de contribuir para as mudanças que se fazem necessárias para a melhoria da ação pedagógica na escola e consequentemente da educação. É certo que conhecer novas teorias, faz parte do processo de construção profissional, mas não bastam, se essas não possibilitam ao professor relacioná-las com seu conhecimento prático construído no seu dia-a-dia (NÓVOA, 1995; PERRENOUD, 200o). Assim, o docente de ensino superior necessita de suportes dentro das instituições para a prática e troca de experiências, estabelecendo uma prática para a formação em serviço, o que, notoriamente, não é uma prática muito difundida no Brasil.

Essa questão merece destaque especial uma vez que o nosso sistema educacional possibilita que pessoas atuem como professores universitários sem nenhuma formação e prática de magistério. A orientação, do ponto de vista legal, é que essa formação se dê em cursos de pós-graduação, preferencialmente em cursos de mestrado e doutorado.

Atualmente os cursos de pós-graduação se dividem em lato sensu (especialização) e stricto sensu (mestrado e doutorado). O título de especialista é dado após o cumprimento de uma carga horária mínima de 360 horas de aula e a entrega de uma monografia. Já ao mestre, além das aulas, é exigido participar de seminários e a apresentação de uma dissertação, com a defesa perante uma banca examinadora. Para o doutor, há um aumento da carga horária e dos seminários, com a entrega e defesa de uma tese, que deve ter caráter 
inédito, para uma banca de exame formada por doutores. Normalmente é cobrado o conhecimento de uma ou duas línguas estrangeiras. Não existe pré-requisito ou exigência, “a priori”, em seguir essa escala; isto é, a pessoa pode ser doutora sem ter o mestrado; mas, o comum é fazer o mestrado e depois o doutorado.

A especialização ou pós-graduação latu sensu tem duração que varia de seis meses a um ano e meio; o mestrado (pós-graduação strictu sensu), em torno de dois anos; e o doutorado (também strictu sensu), aproximadamente de quatro anos. É comum o aluno terminar a graduação e iniciar logo em seguida a pós-graduação, sem ter exercido a profissão, logo tendo uma grande bagagem acadêmica e teórica, mas pouca experiência. $\mathrm{O}$ problema é que esse aluno, quando conclui o mestrado, acaba se transformando em professor universitário sem nunca ter trabalhado no seu ramo; além disso, a pós-graduação stricto sensu é muito mais voltada para a formação do pesquisador do que para a do magistério.

Os estabelecimentos de ensino superior dão preferência à contratação de docentes com pelo menos o mestrado, uma vez que os cursos são avaliados pelo número de mestres e doutores. Assim, temos um profissional que nunca exerceu a profissão e também não preparado para o magistério. Porém, tratam-se, sem dúvida, de jovens brilhantes e com ótima base de conhecimento. Cabe, dessa forma, a tomada de políticas públicas para a complementação da formação de docentes para o ensino superior, em busca da construção de um perfil profissional, em que o ideal é contemplar os aspectos profissionais específicos da área de conhecimento e os pedagógicos (teóricos e práticos). Tais ações devem contribuir para a formação de um perfil de professor universitário.

As possibilidades desta formação recaem, portanto, sobre os cursos de formação docente e, também, precisam ser desenvolvidas pelas próprias instituições, por meio de programas institucionais de formação continuada. As instituições de ensino superior devem ser o lugar de socialização dos conhecimentos acumulados historicamente e também o lugar de geração e criação de novos conhecimentos, gerados por seus professores pesquisadores.

Certamente, são exigidas habilidades diferentes: às vezes, um bom pesquisador não será um bom professor. Para o docente, não é necessário possuir somente o conhecimento, mas também saber como fazer para que os seus alunos possam se apropriar dos 
mesmos, aprendê-los. Como não se forma um profissional apenas com as fundamentações teóricas, é imprescindível o conhecimento prático, que pode ser obtido mediante as experiências da carreira profissional ou mediante a pesquisa e a extensão realizada nas instituições de ensino superior.

Apenas a formação de docentes, em cursos e programas, não é suficiente para compor todo o perfil de um profissional para atuação em salas de aula. Sabe-se que essa formação é eminentemente prática, mediante as próprias experiências e, especialmente, a troca de experiências com os colegas de profissão, em situações que promovam a reflexão sobre os resultados dessas experiências, o que contribui em muito para o desempenho docente.

A problemática do professor no ensino superior, assim, é questionada com toda razão. Os professores, com exceções, deixaram de lado suas principais características em favor apenas do exercício do "notório saber", por meio da pesquisa, publicações, dentre outros. No entanto, como apontado neste trabalho, o docente do ensino superior deve estar atento também às questões de prática profissional e pedagógica, pois somente com a harmonização entre os dois saberes, teremos o proficiente, e tão necessário, profissional docente de ensino superior.

\section{CONSIDERAÇÕES FINAIS}

O estudo proposto em conjunto com as reflexões a respeito da Docência do Ensino Superior permite afirmar que se faz mais que necessário o desenvolvimento de programas voltados à formação pedagógica do professor universitário, bem como promoção de ações que façam despertar o compromisso com as ações educacionais. Mas esta ação não pode se dar de qualquer maneira, nem se limitar aos aspectos práticos da ação pedagógica, restrita às técnicas e metodologias de ensino.

Os docentes do século XXI encontram vários desafios com a revolução tecnológica e com as mudanças na sociedade contemporânea, advindas das reformas neoliberais e da globalização. Têm como objetivo formar cidadãos conscientes e capazes de aprimorar, adquirir e reconstruir o seu conhecimento, sabendo que cada aluno é único, que estão submetidos a condições desiguais. Que sejam capazes de motivar, estimular e acreditar no ser humano e na formação profissional para a pesquisa e a reflexão. 
O professor pesquisador tem função fundamental em todo o processo de ensino e de aprendizagem, pois deixa de ser apenas transmissor de conhecimentos, e passa a dar condições para que seus alunos formulem novos conhecimentos. O desafio, então, que se impõe é o de construir a identidade de professor universitário, baseado não apenas nas experiências vividas e no saber específico, mas também no empenho em construir saberes pedagógicos por meio de uma sólida formação pedagógica e formação continuada, que viabilizem o desenvolvimento de competências necessárias ao exercício do magistério. E que essa formação o conduza a ser um profissional solidário, mais humano, justo, ético, líder, autônomo e reflexivo de sua prática.

Formar no docente a identidade de educador formador e receptivo às necessidades da sociedade e do momento histórico em que está inserido, tornando-se exemplo das características que deve ajudar a formar em seus alunos e revelador das expectativas dos mesmos. A prática deve conter o real teor do significado de docente. Ajudar alguém a adquirir determinado conhecimento é ato nobre e merece valorização e reconhecimento.

\section{REFERÊNCIAS}

AZZI, Sandra. Trabalho docente: autonomia didática e construção do saber pedagógico. In: PIMENTA, Selma Garrido (Org.). Saberes pedagógicos e atividade docente. São Paulo: Cortez, 2000.

BAZZO, Vera Lúcia. Algumas reflexões sobre a profissionalidade docente no contexto das políticas para a Educação Superior. In: RISTOFF, Dilvo; SEVEGNANI, Palmira (Org.). Docência na Educação Superior. Brasília: Instituto Nacional de Estudos e Pesquisas Educacionais Anísio Teixeira, 2006. (Coleção Educação Superior em Debate; v. 5)

BRASIL. Lei no 9.394, de 20 de dezembro de 1996. Estabelece as diretrizes e bases da educação nacional. Disponível em: 〈http://www.planalto.gov.br/ccivil_03/ 9394.htm〉. Acesso em 23/o5/2011.

CALDEIRA, M. S. A apropriação e a construção do saber docente e a prática cotidiana. Cadernos de pesquisa, São Paulo, no 95, p.5-12, novembro de 1995 .

FREIRE, Paulo. Pedagogia da autonomia: saberes necessários à prática educativa. $27^{\underline{a}}$ ed. São Paulo: Paz e Terra, 1996.

LIBÂNEO, José Carlos. Organização e Gestão da Escola: teoria e prática. Goiânia: Alternativa, 2004.

LIBÂNEO, José Carlos. Pedagogia e pedagogos, para quê? São Paulo: Cortez, 1998. 
LIMA, Elvira Souza. A função antropológica de ensinar. Revista Nova Escola, São Paulo, v. 15, n. 138, p. 9-II, Dez. 2000.

MASETTO, Marcos. Docência na Universidade. Campinas: Papirus, 1998

NÓVOA, A. Os professores e a sua formação. Lisboa: Dom Quixote, 1995.

PERRENOUD, P. Io novas competências para ensinar. Porto Alegre: Editora Artmed,2000.

PIMENTA, Selma Garrido; Anastasiou, Lea das Graças C. Docência no ensino superior. São Paulo: Cortez, 2002.

SAVIANI, Dermeval. A nova lei da educação: trajetória, limites e perspectivas. Campinas: Autores Associados, 1998.

VASCONCELOS, Maria Lúcia M. Carvalho. Contribuindo para formação de professores universitários: relato de experiências. In: MASETTO, Marcos Tarciso (Org.). A Docência na universidade. Campinas: Papirus, 1998 (p. 77-93).

ZABALA, Antoni. A prática educativa: como ensinar. Porto Alegre: Editora Artes Médicas Sul Ltda., 1998. 